\title{
Simultaneous in situ hybridisation of native mRNA and immunoglobulin detection by conventional immunofluorescence in paraffin wax embedded sections
}

\author{
S J Harper, J H Pringle, A Gillies, A C Allen, L Layward, J Feehally, I Lauder
}

\begin{abstract}
Aims: The development of a technique for simultaneous in situ hybridisation for native mRNA and conventional immunofluorescence for cytoplasmic antigens in routine pathology specimens. Methods: Cocktails of synthetic deoxyoligonucleotides coding for immunoglobulin J chain and $\boldsymbol{x}$ light chain were 3 ' end labelled enzymatically with digoxigenin using terminal deoxynucleotidyl transferase. Native mRNA sequences were "unmasked" using proteolytic digestion with proteinase $K$ and hybrid detection was achieved with an alkaline phosphatase labelled anti-digoxigenin antibody. Alkaline phosphatase was visualised with Fast red/naphthol AS-MX phosphate. Fluorescein isothiocyanate (FITC) conjugated anti-isotype antibodies were used simultaneously at the detection stage to identify the isotype production by individual plasma cells in endoscopic duodenal biopsy specimens.
\end{abstract}

Results: The IgA plasma cells of the lamina propria were identified by immunofluorescence and hybrids were detected in the anticipated plasma cell population by Fast red visualisation. The reaction product was visible in bright field or ultraviolet illumination which allowed FITC and Fast red labels to be visualised together under ultraviolet light at $490 \mathrm{~nm}$. Dual labelled cells were clearly visible. Morphology was well preserved throughout.

Conclusions: This technique permits the demonstration of specific mRNA species in cells expressing immunoglobulin. It combines all the advantages of non-radioactive synthetic oligonucleotide probes and conventional immunofluorescence techniques in routine formol-saline fixed and parafin wax embedded sections with good retention of morphology.

In situ hybridisation is an important technique for identifying the site of specific gene transcription. ${ }^{12}$ It has distinct advantages over other forms of nucleic acid assays, because it can localise gene expression with cellular accuracy. ${ }^{3}$
This study describes the development of a technique for the detection of specific mRNAs at a cellular level in routinely fixed paraffin embedded tissue sections and the simultaneous demonstration of cytoplasmic antigen by immunofluorescence.

Deoxyoligonucleotide probe cocktails were used to detect mRNA for immunoglobulin $\kappa$ light chain and immunoglobulin J chain genes. These genes are expressed in high copy number in cells actively producing polymeric immunoglobulin. Their use also facilitates the study of mutually and non-mutually exclusive cell populations.

Reliable and reproducible methods for detection of polyadenylated mRNA and immunoglobulin light chain mRNA in formalin fixed paraffin wax sections have been described. ${ }^{24}$ Modification of these techniques results in minimal interference with the immunofluorescent detection of cytoplasmic antigen.

Deoxyoligonucleotide cocktails were 3' labelled with the non-radioactive nucleotide analogue digoxigenin-11-deoxyuridine triphosphate (digoxigenin-11-dUTP). Hybrids were detected by a single step incubation with an alkaline phosphatase labelled antibody and visualised with Fast red/naphthol phosphate. The use of the naphthol AS-MX phosphate produces a reaction product which fluoresces red and permits visualisation of cells expressing specific mRNA species under bright field illumination or ultraviolet light, both under conditions for the detection of tetramethylrhodamine isothiocyanate $(540 \mathrm{~nm})$ and FITC $(490 \mathrm{~nm})$ labels. When using FITC labelled anti-isotype antibodies, double labelled cells appear with a red nuclear signal from mRNA primary transcripts and a green cytoplasmic signal at $490 \mathrm{~nm}$. The presence of a comparable signal strength of both types results in a yellow/ orange fluorescence.

\section{Methods}

PREPARATION OF TISSUE AND SECTIONS

Fresh endoscopic duodenal biopsy specimens less than $3 \mathrm{~mm}$ thick were immersed in formol saline for at least 24 hours. Microscope slides were cleaned and coated with 3-aminopropyltriethoxysilane as previously described. Paraffin wax embedded sections $(4 \mu \mathrm{m})$ were cut on to slides and allowed to dry overnight at

\author{
Correspondence to \\ Dr S J Harper \\ Accepted for publication \\ 27 August 1991 \\ Department of \\ General Hospital, \\ Pathology, University \\ J H Pringle
}


$37^{\circ} \mathrm{C}$. Sections were then dewaxed and rehydrated through a series of washes in fresh xylene, ethanol, and diethylpyrocarbonate treated ultra-pure water (DEPC-water). To avoid ribonuclease contamination all subsequent steps were performed with gloved hands and sterile instruments. All solutions and equipment used in pretreatment and hybridisation stages were also appropriately treated.

\section{PRETREATMENTS}

To unmask native mRNA target sequences and expose immunoglobulin epitopes pretreatments were required. These were adapted from previously reported techniques. ${ }^{45}$ After dewaxing and rehydration slides were immersed in $50 \mathrm{mM}$ TRIS-HCl, $\mathrm{pH} 7 \cdot 65$, in DEPCwater (TRIS-HCl), then digested in proteinase K (Boehringer Mannheim, Germany, 161519) solutions in TRIS- $\mathrm{HCl}$ at concentrations in the range 1 to $10 \mu \mathrm{g} / \mathrm{ml}$ for one hour at $37^{\circ} \mathrm{C}$. After this sections were washed in DEPC-water at $4^{\circ} \mathrm{C}$ for 10 minutes.

Appropriate RNAse pretreatment controls were performed at this stage to run in parallel with the experimental slides. RNAse type A1 (DNAse-free) (Sigma UK, R4875) digests were performed at a concentration of $100 \mu \mathrm{g} / \mathrm{ml}$ in $2 \times \mathrm{SSC} / 10 \mathrm{mM} \mathrm{MgCl}$ at $37^{\circ} \mathrm{C}$ for one hour. Slides not receiving $\mathrm{RNAse}$ type $\mathrm{Al}$ were incubated in $2 \times \mathrm{SSC} / 10 \mathrm{mM} \mathrm{MgCl} / \mathrm{DEPC}$ under the same conditions. (SSC $=150 \mathrm{mM}$ $\mathrm{NaCl}, 15 \mathrm{mM}$ trisodium citrate, $\mathrm{pH} 7 \cdot 0$ ). After one hour slides were washed in phosphate buffered saline/DEPC (PBS/DEPC) for 10 minutes at $4^{\circ} \mathrm{C}$, postfixed in $0.4 \%$ paraformaldehyde in PBS/DEPC at $4^{\circ} \mathrm{C}$ for 10 minutes, and finally washed in DEPC-water.

\section{OLIGONUCLEOTIDE SYNTHESIS}

Deoxyoligonucleotides were synthesised by phosphoramidite chemistry ${ }^{6}$ using a DNA synthesiser, model 380B (Applied Biosystems, USA). Individual deoxyoligonucleotides were 30 bases long and were prepared on $0.2 \mathrm{ml}$ columns. J chain oligonucleotide design was based on the J chain gene sequence published by Max and Korsmeyer. ${ }^{7}$ Similarly, for $\kappa$ light chain, deoxyoligonucleotides were derived from sequence data previously described. ${ }^{8-10}$ For $\kappa$ light chain, sequences were chosen for the conserved constant region. Coding sequences were used in both cocktails which showed no obvious homologies with other mRNAs in the European Molecular Biology Library sequence database. Base additions were made using 0-(2-cyanoethyl)-N,N-diisopropylphosphoramidites (Cruachem UK). ${ }^{11}$ Crude oligomers were then desalted by ethanol precipitation, evaporated to dryness, dissolved in DEPC-water and assayed by ultraviolet light (Applied Biosystems Ltd User Bulletin 1986).

\section{OLIGONUCLEOTIDE LABELLING}

Deoxyoligonucleotide labelling was achieved using a terminal deoxynucleotidyl transferase 3 'end labelling reaction adapted from a previously described technique. ${ }^{4}$ Heteropolymer tail labelling was achieved with the non-radioactive nucleotide analogue digoxigenin-11-dUTP (Boehringer Mannheim, Germany, 1093088). Deoxyadenosine triphosphate was used as a "spacer" to facilitate multiple digoxigenin-11-dUTP additions. Labelled oligonucleotides were purified through Sephadex G50 spun columns prepared with TRIS-EDTA, $0 \cdot 1 \%$ sodium dodecyl sulphate.

HYBRIDISATION AND POST HYBRIDISATION

Excess fluid was removed from previously drained slides which were then flooded with $200 \mu \mathrm{l}$ of hybridisation buffer. The J chain hybridisation cocktail contained $20 \%$ formamide (v/v), the $\kappa$ cocktail $50 \%$. Slides were then placed in a humid chamber and maintained at $37^{\circ} \mathrm{C}$ for one hour in a hot air incubator. After this stage the slides were again drained and $50 \mu \mathrm{l}$ of hybridisation buffer containing labelled deoxyoligonucleotide probe cocktail was added. Probe concentrations of $200 \mathrm{pg} / \mu \mathrm{l}$ for $\mathrm{J}$ chain, $500 \mathrm{pg} / \mu \mathrm{l}$ for $\kappa$ light chain were used. Sections were then covered with siliconised coverslips (dimethyl dichlorosilane), returned to the humid chamber and incubator, and maintained at $37^{\circ} \mathrm{C}$ overnight.

After hybridisation slides were transferred to $2 \times \mathrm{SSC} / 30 \%$ formamide (v/v) prewarmed to $37^{\circ} \mathrm{C}$. Post hybridisation washes then took the form of two 10 minute washes in $2 \times \mathrm{SSC} / 30 \%$ formamide $(v / v)$ at $37^{\circ} \mathrm{C}$, followed by two further 10 minute washes in $2 \times$ SSC at room temperature. No formamide was used in the $\kappa$ post hybridisation washes. Finally sections were placed in TRIS-buffered saline (TBS) $(50$ mM TRIS-HCl, $0 \cdot 15 \mathrm{M} \mathrm{NaCl}, 2 \mathrm{mM} \mathrm{MgCl}_{2}$ $\mathrm{pH} 7 \cdot 6$ ) containing 3\% bovine serum albumin (Sigma UK, A7906), 0.1\% Triton-X-100 (Merck UK 30632) at room temperature for at least 15 minutes.

PROBE AND IMMUNOGLOBULIN DETECTION

A sensitive single step detection system was used to detect subpicogram concentrations of labelled probe. Slides were flooded in TBS containing 1:600 alkaline phosphatase labelled sheep polyclonal anti-digoxigenin antibody (Boehringer Mannheim, Germany, 1093274) and 1:5 FITC conjugated rabbit $\mathrm{F}\left(\mathrm{ab}^{\prime}\right)_{2}$ antihuman IgA (Dako UK, F316) or 1:5 FITC conjugated polyclonal sheep anti-human $\kappa$ (The Binding Site, UK, PF015) for $30 \mathrm{~min}$ utes. Slides were washed in TBS for five minutes and then transferred to demonstration solution for one hour. Demonstration solution took the form of Fast red (Sigma UK, F-1500) $50 \mathrm{mg}$; Levamisole (Sigma UK, L-9756) 24 mg; naphthol AS-MX phosphate (Sigma UK, $\mathrm{N}-5000) 50 \mathrm{mg}$; (predissolved in dimethylformamide) in $100 \mathrm{ml}$ veronal acetate buffer, $\mathrm{pH}$ $9 \cdot 2$, and was filtered prior to use. After incubation, slides were washed in ultra-pure water and mounted in aqueous mounting medium. After initial inspection the sections were counterstained if required with Mayer's haematoxylin.

\section{MICROSCOPICAL EXAMINATION}

A Nikon Optiphot microscope was used for bright field microscopy and conventional 

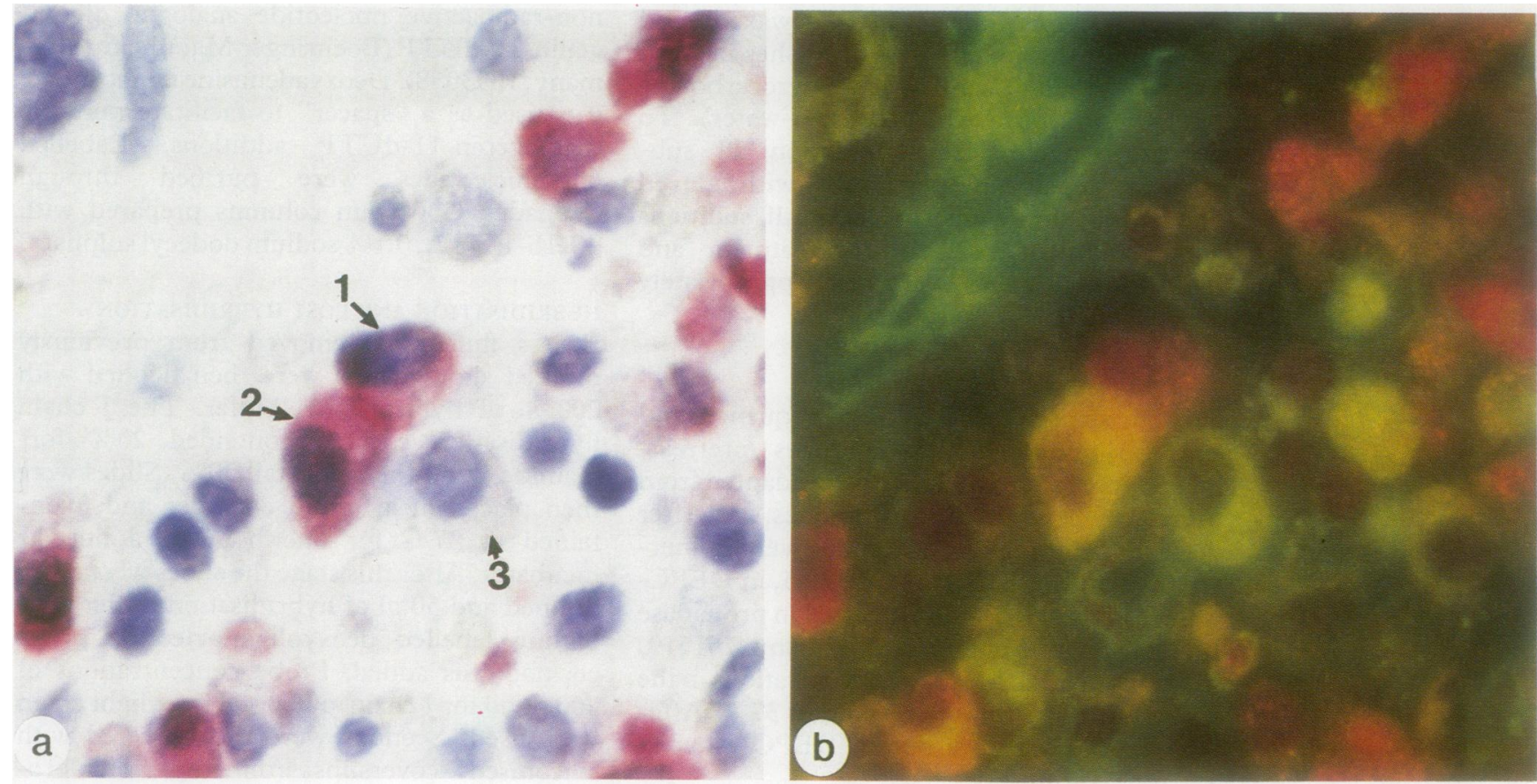

Figure 1 Simultaneous in situ hybridisation for J chain $m R N A$ (red) and immunofluorescence for cytoplasmic IgA (green). (1A) In situ hybridisation for $J$ chain $m R N A$ using a digoxigenin labelled deoxyoligonucleotide probe on a formol-saline fixed duodenal biopsy specimen. Fast red signal, Mayer's haematoxylin counterstain. Cells 1 and 2 positive, cell 3 negative. (1B) The same field showing $J$ chain $m R N A$ (red) and immunofluorescence for cytoplasmic IgA (green). Cell 1 negative for IgA, cell 2 positive (double labelled), cell 3 positive. (1C) A composite confocal picture of cells 1,2, and 3, red and green channels merged.

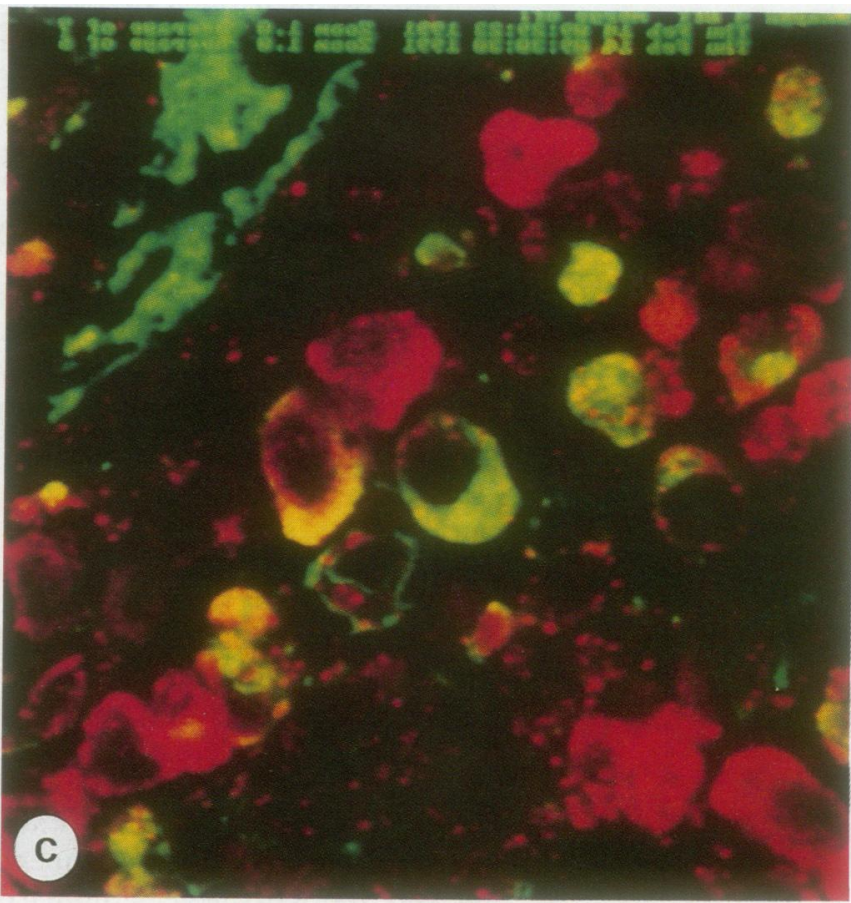

fluorescence microscopy. Confocal advanced light microscopy was performed on a MRC600 confocal laser scanning microscope. An Argon laser was used with maximum emissions at 488 $\mathrm{nm}$ and $514 \mathrm{~nm}$.

\section{Results}

IN SITU HYBRIDISATION WITH J CHAIN AND $\kappa$ LIGHT CHAIN PROBES

Sites of hybridisation visualised with Fast red specifically stained the anticipated target plasma cell and lymphocyte population in the lamina propria of duodenal biopsy specimens. Both deoxyoligonucleotide probe cocktails, J chain (fig 1A) and $\kappa$ (fig 2B), produced sharp, well defined signal with negligible background staining. Excellent morphological preservation was seen throughout. Before counterstaining, strong cytoplasmic signal (and weaker nuclear signal) was seen in plasma cells with both probes.
SIGNAL SPECIFICITY

Appropriate controls were carried out with each experiment and run in parallel with experimental slides. Control slides for the detection system were performed in exactly the same reaction conditions as all other slides, but in the absence of probe no signal was seen on any occasion. Signal was also eliminated from slides which underwent RNAse A1 pretreatment. Kappa probe specificity was also confirmed by northern blotting. The $\mathrm{J}$ chain probe was derived from a published $\mathrm{CDNA}$ sequence. The Pvu II/Xba I exon four J chain probe derived from this sequence has been used in northern blot analysis to study J chain mRNA transcription in human pre-B and B cell lines. ${ }^{7}$

\section{PRETREATMENTS/PROBE CONCENTRATIONS/} DETECTION

Pretreatments were adapted from those previously described. ${ }^{24}$ The most important 

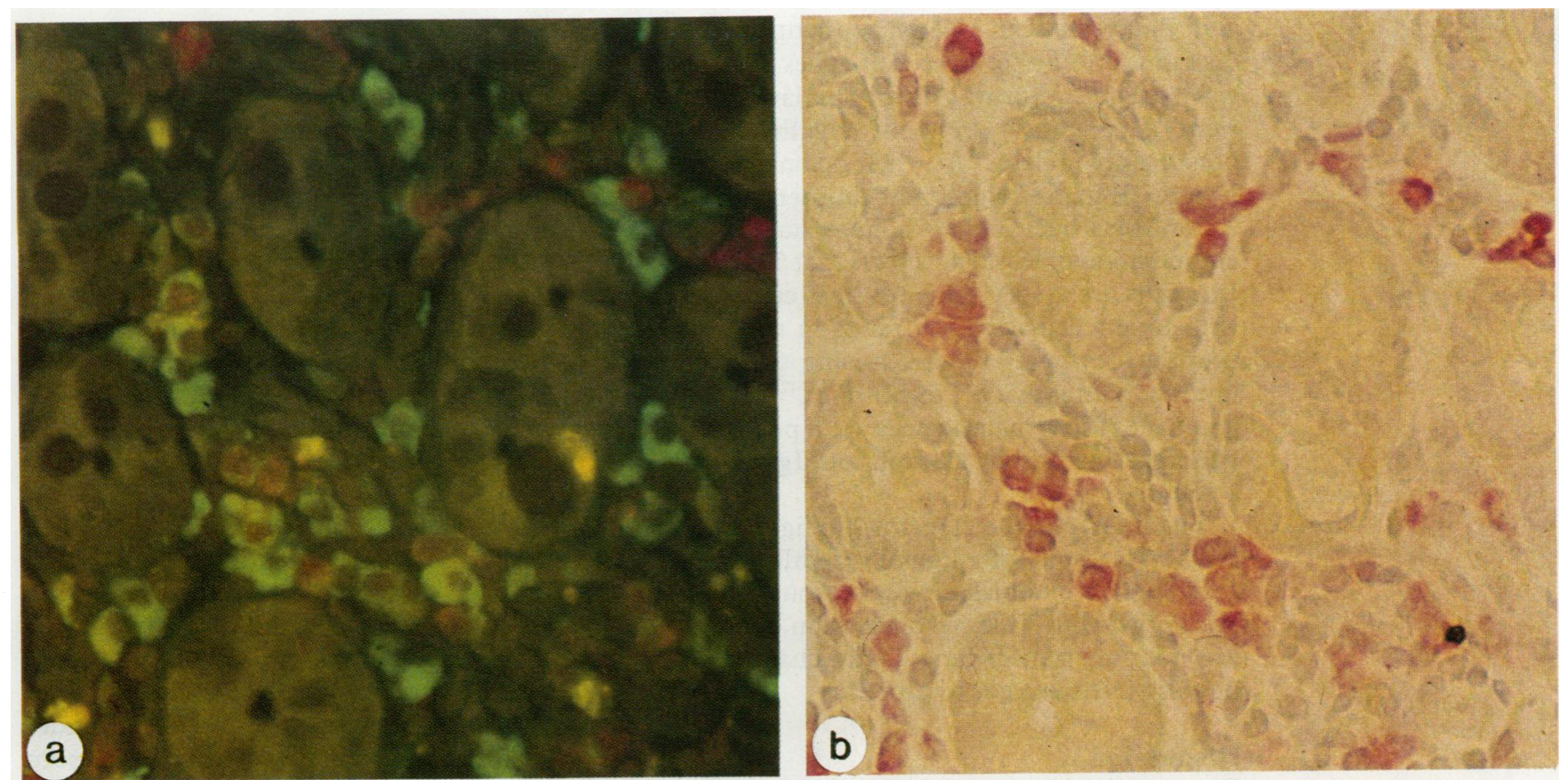

Figure 2 In situ hybridisation detection of $\kappa$ light chain $m R N A$ and IgA by immunofluorescence. (2A) Kappa light chain mRNA (red) and immunofluorescence for cytoplasmic IgA (green). Double labelled cells are seen with red nuclear and green cytoplasmic signal, (viewed before counterstaining). ( $2 B$ ) Bright field counterpart of $(2 A)$. In situ detection of $\kappa$ light chain $m R N A$ using a digoxigenin labelled oligonucleotide probe on a formol saline fixed duodenal biopsy specimen (viewed after counterstaining with Mayer's haematoxylin).

pretreatment is that of proteinase $\mathrm{K}$ digestion. This unmasks native mRNA and exposes cytoplasmic antigens in an analogous manner to the use of trypsin for immunofluorescent examination of paraffin wax sections. The best compromise between signal intensity and retained morphology in all duodenal biopsy specimens was seen with proteinase $K$ concentrations of 2 $\mu \mathrm{g} / \mathrm{ml}$.

The optimal probe concentration was found to be $200 \mathrm{pg} / \mu \mathrm{l}$ for the J chain cocktail and 500 $\mathrm{pg} / \mu \mathrm{l}$ for $\kappa$ light chain. Higher concentrations produced slight background staining. Lower intensity signal was seen at much lower probe

Figure 3 In situ hybridisation of $\kappa$ light chain $m R N A$ (red) and $x$ light chain by immunofluorescence (green). Highlighted cell (arrow) has red nuclear signal of $\kappa$ light chain $m R N A$ and green cytoplasmic signal of $\kappa$ light chain. concentrations; as low as $25 \mathrm{pg} / \mu \mathrm{l}$ with the $\mathrm{J}$ chain probe.

Dual detection of hybrids and cytoplasmic antigens was achieved using an alkaline phosphatase labelled anti-digoxigenin antibody simultaneously with FITC labelled immunoglobulins. Although the two detection stages can be performed sequentially (FITC labelled immunoglobulin incubation being performed immediately before post fixation), we found no advantage in this over the simultaneous method.

Figs $1 \mathrm{~A}$ and $\mathrm{B}$ are higher power oil immersion $(\times 1000)$ photomicrogaphs. Fig 1A illustrates the expression of $J$ chain mRNA in the plasma cell population of the duodenal lamina propria and Fig 1B the simultaneous demonstration of cytoplasmic IgA. Figs $1 \mathrm{~A}$ and $1 \mathrm{~B}$ represent the same field viewed after counterstaining with Mayer's haematoxylin. The field was photographed sequentially, initially under bright field illumination (fig $1 \mathrm{~A}$ ) and then under ultraviolet-excitation wavelength 490 nm (fig 1B). Cell 1 expresses J chain mRNA (red signal) but has no green (IgA) signal. In contrast, cell 3 is negative for J chain mRNA but positive for cytoplasmic IgA by immunofluorescence. Cell 2 is strongly positive for both, producing a yellow/orange signal. Fig $1 \mathrm{C}$ shows the same three cells analysed with the confocal microscope. This is a composite picture of both red and green channels after each was independently digitalised, optimally focused, and normalised.

mRNA $\kappa$ light chain and simultaneous $\operatorname{IgA}$ detection is illustrated in fig $2 \mathrm{~A}(\times 400)$. Double staining in this preparation viewed under ultraviolet $(490 \mathrm{~nm})$ before counterstaining produces a red nuclear signal within a green cytoplasmic signal of $\operatorname{IgA}$. Double labelled cells, cells positive for $\kappa$ and negative for $\operatorname{IgA}$, 
and vice-versa, can clearly be identified. The distribution of the three cell types identified was seldom uniform; cells of similar labelling were frequently grouped together. This presumably relates to their clonal origin. Figure $2 B$ is the bright field counterpart to fig $2 \mathrm{~A}$ and has been lightly counterstained. Cell enumeration of this field shows that $58 \%$ of the IgA cells are $\kappa$ IgA. This result is comparable with total $\kappa: \lambda$ plasma cell ratios in the lamina propria previously reported using two colour immunofluorescence techniques. ${ }^{12}$ Twelve percent of the visualised cells are $\kappa$ positive but IgA negative, and by assumption, IgM or IgG $\kappa$ cells.

The highlighted cell (arrow) in fig 3 shows a red nuclear stain for $\kappa$ light chain mRNA and a green/yellow cytoplasmic signal from cytoplasmic light chain. This cell on fixation, therefore, was not only transcribing $\kappa$ light chain mRNA but also translating it to protein.

\section{Discussion}

Factors affecting the efficiency of native mRNA preservation and detection are multiple and have been fully described elsewhere. ${ }^{2}$ There are four additional factors relevant in this extension of a standard in situ hybridisation technique.

(i) Fixation: A protocol is required which is suitable for the efficient preservation of both mRNA species and cytoplasmic epitopes. We have found that $24-48$ hours in $10 \%$ formol saline fulfils this requirement. Less than 24 hours may be insufficient for optimal mRNA preservation. In contrast, prolonged fixation results in the need for more aggressive proteolytic digestion with proteinase $K$, reducing cytoplasmic immunofluorescent signal and disrupting normal morphology.

(ii) Pretreatments that minimise the loss of cytoplasmic epitopes: Endoscopic duodenal biopsy specimens examined in this study required mild proteolytic digestion; this contrasts with higher concentrations of proteinase $\mathrm{K}$ required with larger tissue specimens. ${ }^{2}$ Strong acid and hot salt washes were avoided because they badly affected cytoplasmic epitope preservation.

(iii) Signal to noise ratio: This depends on probe label concentration and on stringency. The probe label digoxigenin has many advantages over other forms of non-isotope nucleotide analogues (Biotin, for example). It has a simple detection step involving a single antibody without the need for amplification. This readily allows for simultaneous use of FITC labelled immunoglobulins. We have found the results from simultaneous detection with a biotin-streptavidin detection system disappointing because of background staining and weak immunofluorescent signal (unpublished observations). Stringency studies showed that to reduce non-specific hybridisation with the $\mathrm{J}$ chain probe $30 \%$ formamide was required in the post hybridisation washes. This may reflect the relatively high AT content of the J chain probe relative to that of the $\kappa$ cocktail.

(iv) The use of naphthol $A S-M X$ phosphate: In combination with Fast red this produces a reaction product visible under bright field illumination and ultra violet. ${ }^{13}$ In contrast to FITC, this fluorochrome is relatively stable to exposure and storage, although some deterioration does occur with prolonged storage-the signal becoming granular in appearance and much less distinct.

Confocal microscopy permits simultaneous dual fluorochrome image digitalisation and storage. It also allows the signal intensity of the Fast red/naphthol phosphate reaction product to be quantified. Label intensity has been related to total hybridised probe and therefore copy number of the target nucleic acid sequence. $^{14}$

Accurate and interpretable double labelling, particularly in non-mutually exclusive cell populations, depends on a balance of two signals. Hence sections are initially viewed before counterstaining under bright field illumination and cells positive for hybrids are noted; if the section is then visualised under ultraviolet light, double stained cells are seen with red nuclear staining from primary RNA transcripts and green cytoplasmic signal from cytoplasm bound FITC labelled antibodies. The cytoplasmic signal may be yellow or orange, depending on relative signal intensities. If sections are not viewed before counterstaining fluorescence intensity (both red and green) may be significantly reduced and double labelled signals missed because this procedure almost uniformly blocks fluorescence signal from nuclear hybrids.

The study of $\mathrm{J}$ chain expression in $\operatorname{IgA}$ producing plasma cells of the duodenal lamina propria using this technique showed individual cells that were $\mathrm{J}$ chain mRNA negative, although most ( $>90 \%$ ) IgA cells were J chain positive. This compares with previously published data using immunological techniques which showed that $97.3 \%$ of distal ileal IgA cells were $\mathrm{J}$ chain positive and $2 \cdot 7 \% \mathrm{~J}$ chain negative. ${ }^{15}$ These are presumably monomeric IgA cells which may make up a small percentage of the duodenal mucosal IgA system, the primary function of which is to produce polymeric IgA for active secretion into the duodenal lumen. Alternatively, they may represent polymeric IgA cells in which J chain mRNA transcription has stopped.

Recent reports have elegantly shown methods for the simultaneous analysis of cell surface antigens and markers of DNA content, cell proliferation, and cell cycle kinetics. ${ }^{13}{ }^{16}$ Simultaneous immunocytochemistry and in situ hybridisation has also been described. ${ }^{17-20}$ Several studies have described the use of diaminobenzidine or avidin-biotin cytochemistry in combination with radioactively labelled probes; $;^{17}$ other reports described the use of biotinylated probes in conjunction with immunocytochemistry to identify viral genomic sequences in paraffin wax embedded human tissue. ${ }^{1920}$ In addition, methods for triple colour fluorescent in situ hybridisation and fluorescent in situ hybridisation in combination with immunofluorescent staining for cell surface markers have been described, ${ }^{2122}$ although these techniques have only been 
applied to freshly harvested human blood lymphocytes or cultured cell lines, and not to routinely processed tissue specimens.

In conclusion, the combination of in situ hybridisation and conventional immunofluorescence on paraffin wax embedded sections permits the simultaneous demonstration of native mRNA transcription and protein translation in the same cell or cells from routine and archival human material with good retention of morphology. This method adds to previously described dual labelling techniques and we hope it may contribute to the field of molecular pathology by facilitating the study of the sites of gene expression and protein synthesis in cell populations within their normal topographical surroundings.

SJH is supported by Bayer (UK) Ltd. SJH thanks Messrs $T$ Carroll, J Hattersley, and $H$ Stockley for continued advice and support, and Mrs S Locke for technical expertise.

1 Coghlan JP, Aldred P, Haralambidis J, Niall HD, Penschow JD, Tregear GW. Review: Hybridization histochemistry. Anal Biochem 1985;149:1-28.

2 Pringle JH, Ruprai AK, Primrose L, et al. In situ hybridisation of immunoglobulin light chain mRNA in paraffin sections using biotinylated or hapten-labelled oligonucleotide probes. J Pathol 1990;162:197-207.

3 Warford A, Lauder I. In situ hybridisation in perspective $J$ Clin Pathol 1991;44:177-81.

4 Pringle JH, Primrose L, Kind CN, Talbot IC, lauder I. In situ hybridization demonstration of poly-adenylated RNA situ hybridization demonstration of poly-adenylated RNA sequences in formalin-fixed paraffin sections using a
biotinylated oligonucleotide poly $\mathrm{d}(\mathrm{T})$ probe. J Pathol biotinylated oligo

5 Cox KH, Deleon DV, Angerer LM, Angerer RC. Detection of mRNAs in sea urchin embryos by in situ hybridization using asymmetrical RNA probes. Dev Biol 1984;101: 485-502.

6 Beaucage SL, Caruthers MH. Deoxynucleoside phosphoramidites-A new class of key intermediates for deoxypolynucleotide synthesis. Tetrahedron Lett deoxypolynucleot

7 Max EE, Korsmeyer SJ. Human J chain gene. J Exp Med 1985;161:832-49.

8 Blackwell TW, Alt FW. Immunoglobulin genes. In: Hames BD, Glover DM, eds. Molecular immunology: 1988:1-60
9 Hieter PA, Max EE, Seidman JG, Maizel JV, Leder P. Cloned human and mouse kappa immunoglobulin constant $\mathrm{J}$ region genes conserve homology in functional segments. Cell 1980;22:197-202.

10 Hedrick SM, Nielson EA, Kavaler J, Cohen DI, Davis MM. Sequence relationships between putative $T$-cell receptor polypeptides and immunoglobulins. Nature 1984; 308:153-8

11 McBride LJ, Eadie JS, Efcavitch JW, Andrus WA. Base modification and the phosphoramidite approach. Nucleosides Nucleotides 1987;6:297-300.

12 Hené RJ, Schuurman H-J, Kater L. Immunoglobulin A subclass-containing plasma cells in the jejumun in primary IgA nephropathy and in Henoch-Schönlein purpura. Nephron 1988;48:4-7.

13 Murdoch A, Jenkinson EJ, Johnson GD, Owen JJT. Alkaline phosphatase-Fast Red, a new fluorescent label. Application in double labelling for cell surface antigen and cell cycle analysis. J Immunol Methods 1990;132:45-9.

14 Lawrence JB, Singer RH. Quantitative analysis of in situ hybridization methods for the detection of actin gene hybridization methods for the detection of actir

15 Bjerke K, Brandtzaeg P. Terminally differentiated human intestinal $B$ cells. J chain expression of IgA and IgG subclass-producing immunocytes in the distal ileum compared with mesenteric and peripheral lymph nodes. Clin Exp Immunol 1990;82:411-5.

16 Bayer JA, De Vries P, Herweijer H, Bauman GJ. The use of E coli exonuclease III to generate single stranded DNA in BrdUrd cell-cycle analysis permits simultaneous detection of cell surface antigens. $J$ Immunol Methods 1990;132:13-24.

17 Brahic M, Haase AT, Cash E. Simultaneous in situ detection of viral RNA and antigens. Proc Natl Acad Sci USA 1984;81:5445-8.

18 Shivers BD, Harlan RE, Pfaff DW, Schachter BS. Combination of immunocytochemistry and in situ hybridization in the same tissue section of rat pituitary. $J$ Histochem Cytochem 1986;34:39-43.

19 McQuaid S, Isserte S, Allan GM, Taylor MJ, Allen IV Cosby SL. Use of immunocytochemistry and biotinylated in situ hybridisation for detecting measles virus in central nervous system tissue. J Clin Pathol 1990;43:329-33.

20 Porter HJ, Heryet A, Quantrill AM, Fleming KA. Combined non-isotopic in situ hybridisation and immunohistochemistry on routine paraffin wax embedded tissue: identification of cell type infected by human parvovirus and demonstration of cytomegalovirus DNA and antigen in renal infection. J Clin Pathol 1990;43:129-32.

21 Nederlof PM, Robinson D, Abuknesha R, Wiegant J, Hopman AH, Tanke HJ, Raap AK. Three-color fluorescence in situ hybridization for the simultaneous detection of multiple nucleic acid sequences. Cytometry 1989;10: $20-7$.

22 Bakkus MHC, Brakel-van Peer KMJ, Adriaansen HJ, et al Detection of oncogene expression by fluorescent in situ hybridization in combination with immunofluorescen staining of cell surface markers. Oncogene 1989;4:1255-62. 